\title{
Viability of Primary Human Pigment Epithelium Cells and Muller-Glia Cells after Intravitreal Ziv-Aflibercept and Aflibercept
}

\author{
Gabriel Costa de Andrade ${ }^{\mathrm{a}} \quad$ Christian Wertheimer $^{\mathrm{b}} \quad$ Kirsten Eibl $^{\mathrm{b}} \quad$ Armin Wolf $^{\mathrm{b}}$ \\ Anselm Kampik ${ }^{b}$ Eduardo Buchele Rodrigues ${ }^{a}$ Michel Eid Farah ${ }^{a}$ \\ Christos Haritoglou ${ }^{a}$ \\ a Department of Ophthalmology, Federal University of São Paulo, São Paulo, Brazil; bepartment of Ophthalmology, \\ Ludwig-Maximilian-University, Munich, Germany
}

\section{Keywords}

Ziv-aflibercept · Aflibercept · Toxicity

\begin{abstract}
Purpose: The aim of this study was to access the safety profiles of 2 fusion proteins with anti-vascular endothelial growth factor action (ziv-aflibercept and aflibercept) on retinal pigment epithelium cells and Muller-Glia cells in culture by assessing cell viability post drug exposure. Methods: Primary human retinal pigment epithelium cells ( $p R P E)$ and Muller-Glia cells (Mio-M1) were exposed to the clinical standardized concentrations of ziv-aflibercept $(25 \mathrm{mg} / \mathrm{mL})$ and aflibercept (40 mg/mL). Progressively higher concentrations of $\mathrm{NaCl}(300,500,1,000,1,500,2,000,5,000$, and 10,000 $\mathrm{mosm} / \mathrm{kg}$ ) were also applied to cells to assess the possibility of potentiating hyperosmotic cytotoxity effect. The study was applied to measure pRPE and Mio-M1 viability by a tetrazolium dye-reduction assay (XTT). Results: Cell viability of both pRPE and Mio-M1 presented no significant changes after exposure of ziv-aflibercept and aflibercept. Progressive $\mathrm{NaCl}$ concentrations did not significantly alter cell viability. The exposure to the negative control of $75 \mu \mathrm{L} / \mathrm{mL}$ of dimeth-
\end{abstract}

\section{KARGER}

(c) 2017 S. Karger AG, Basel

E-Mail karger@karger.com

www.karger.com/oph yl sulfoxide showed significant reduction in cell viability. Conclusions: At clinical doses, neither ziv-aflibercept nor aflibercept caused any significant reduction in cell viability in vitro. Furthermore, injection solutions of $\mathrm{NaCl}$ with higher osmolality caused no significant reduction in cell viability.

두 2017 S. Karger AG, Basel

\section{Introduction}

Ocular abnormal angiogenesis is the root of most of the main causes of blindness worldwide such as neovascular age-related disease (AMD) and macular edema secondary to diabetes or vein occlusions [1]. Vascular endothelial growth factors (VEGF) are identified as the principal mediators of new blood vessel growth and are key regulators of vascular permeability [2]. The fusion proteins, such as ziv-aflibercept (Zaltrap; Regeneron, Tarrytown, NY, USA) and aflibercept (Eylea, Regeneron Phar-

Gabriel Costa de Andrade and Christian Wertheimer contributed equally to this paper. 
Fig. 1. The change in cell viability in the XTT assay observed for aflibercept or zivaflibercept $(p>0.05)$ in Muller-Glia cells in comparison to the control was not significant. Furthermore, a change in osmolality in the injection solution up to 10,000 $\mathrm{mosm} / \mathrm{kg}$ did not cause any change in cell viability in comparison to the untreated control. A significant decrease was observed in the negative control of $75 \mu \mathrm{L} / \mathrm{mL}$ DMSO.

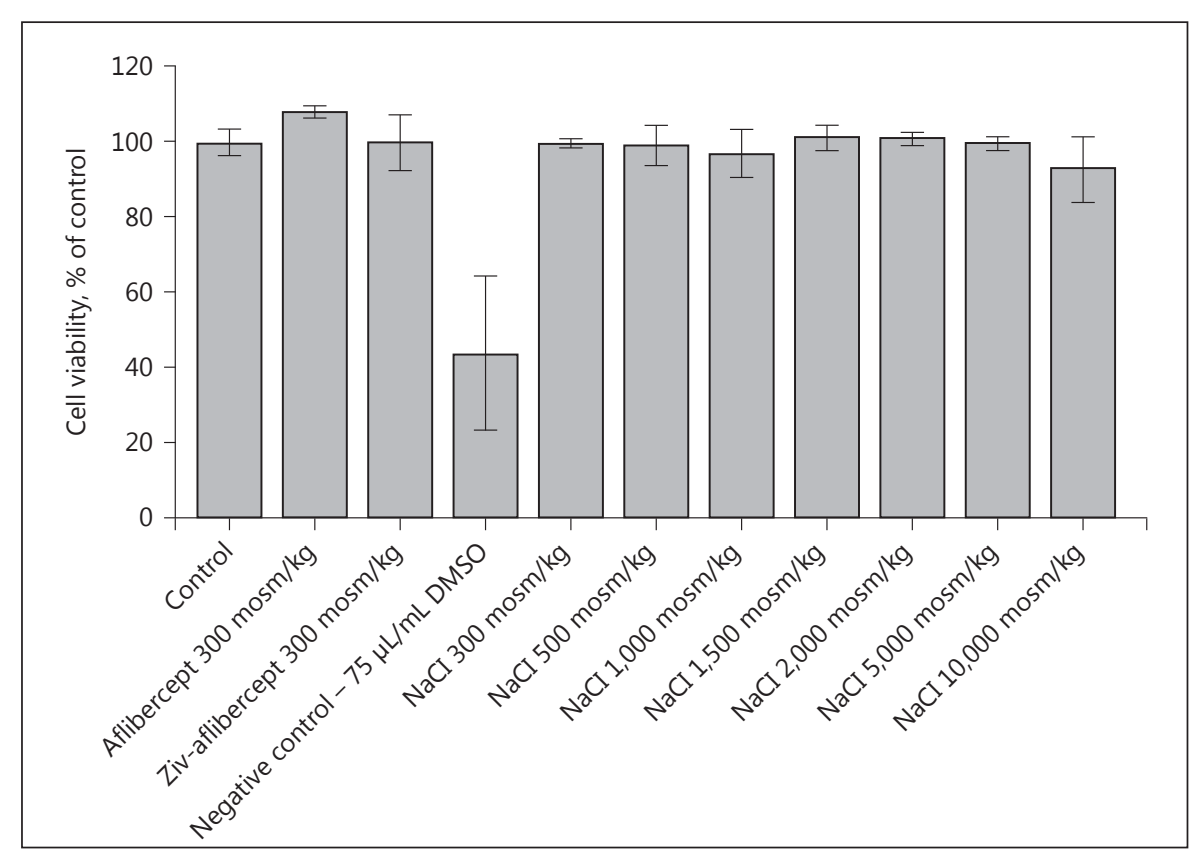

maceuticals), are the most recent anti-angiogenic treatment with some advantages compared to prior options, ranibizumab (Lucentis, Genentech) and bevacizumab (Avastin, Genentech) because it binds multiple members of the VEGF family, with high affinity for the VEGF-A and placental growth factor (PlGF) isoforms [3]. These isoforms play a key role in the development of the choroidal neovascularization associated with exudative AMD and in vascular hyperpermeability associated with macular edema [4]. Additionally, the prolonged intravitreal half-life of aflibercept compared with ranibizumab can translate to a lower treatment load in terms of injections, monitoring, and medical visits [4].

Ziv-aflibercept was approved by the FDA in August 2012 for the treatment of patients with malignant colorectal tumors [5]. Its ophthalmic use is considered off-label. Ziv-aflibercept and aflibercept have the same structure and exert the same function, but aflibercept undergoes a different purification process and contains different buffer solutions resulting in a compound of lower osmolality (300 vs. $1,000 \mathrm{mosm} / \mathrm{kg}$ ) and possibly less toxicity [6]. In order to assess the safety of ziv-aflibercept and other antiVEGF agents, Malik et al. [7] conducted a study to evaluate the effects of different concentrations of the four antiVEGF agents previously cited in an experimental model of human retinal pigment epithelium cells. The study showed mild toxicity of bevacizumab and ziv-aflibercept at clinical doses [7].
Even after this in vitro study, consecutive clinical studies had been published demonstrating the safety and efficacy of ziv-aflibercept in the treatment of macular diseases [8-10]. For instance, de Andrade et al. [10] showed good results in the treatment of diabetic macular edema with ziv-aflibercept resulting in improvement in best corrected visual acuity (BCVA) and reduction in central retinal thickness (CRT) and no signs of ocular or systemic toxicity in all treated patients. De Oliveira Dias et al. [8] also tested ziv-aflibercept in a patient with AMD, also with improvement in BCVA and CRT and no signs of toxicity.

The primary purpose of this study was to investigate the safety profiles of aflibercept and ziv-aflibercept on primary human retinal pigment epithelium cells (pRPE) and Muller-Glia cells (Mio-M1). The secondary goal of the study was to evaluate the potential toxicity of progressively higher concentrations of $\mathrm{NaCl}$ (with different osmolality) on pRPE and Mio-M1 cells. The method applied for the experiment was the tetrazolium dye-reduction (XTT) assay.

\section{Methods}

Solutions of Different Osmolality: Aflibercept, Ziv-Aflibercept and Sterile $\mathrm{NaCl}$

Aflibercept $\left(\right.$ Eylea $^{\circledR}$, Bayer, Leverkusen, Germany) and zivaflibercept (Zaltrap ${ }^{\circledR}$, Regeneron, Tarrytown, NY, USA) were used in the same concentration as when used during routine intravit- 
Fig. 2. The change in cell viability in the XTT assay observed for aflibercept or zivaflibercept $(p>0.05)$ in primary human retinal pigment epithelium cells of donor 1 in comparison to the control was not significant. Furthermore, a change in osmolality in the injection solution up to 10,000 $\mathrm{mosm} / \mathrm{kg}$ did not cause any change in cell viability in comparison to the untreated control. A significant decrease was observed in the negative control of $75 \mu \mathrm{L} / \mathrm{mL}$ DMSO.

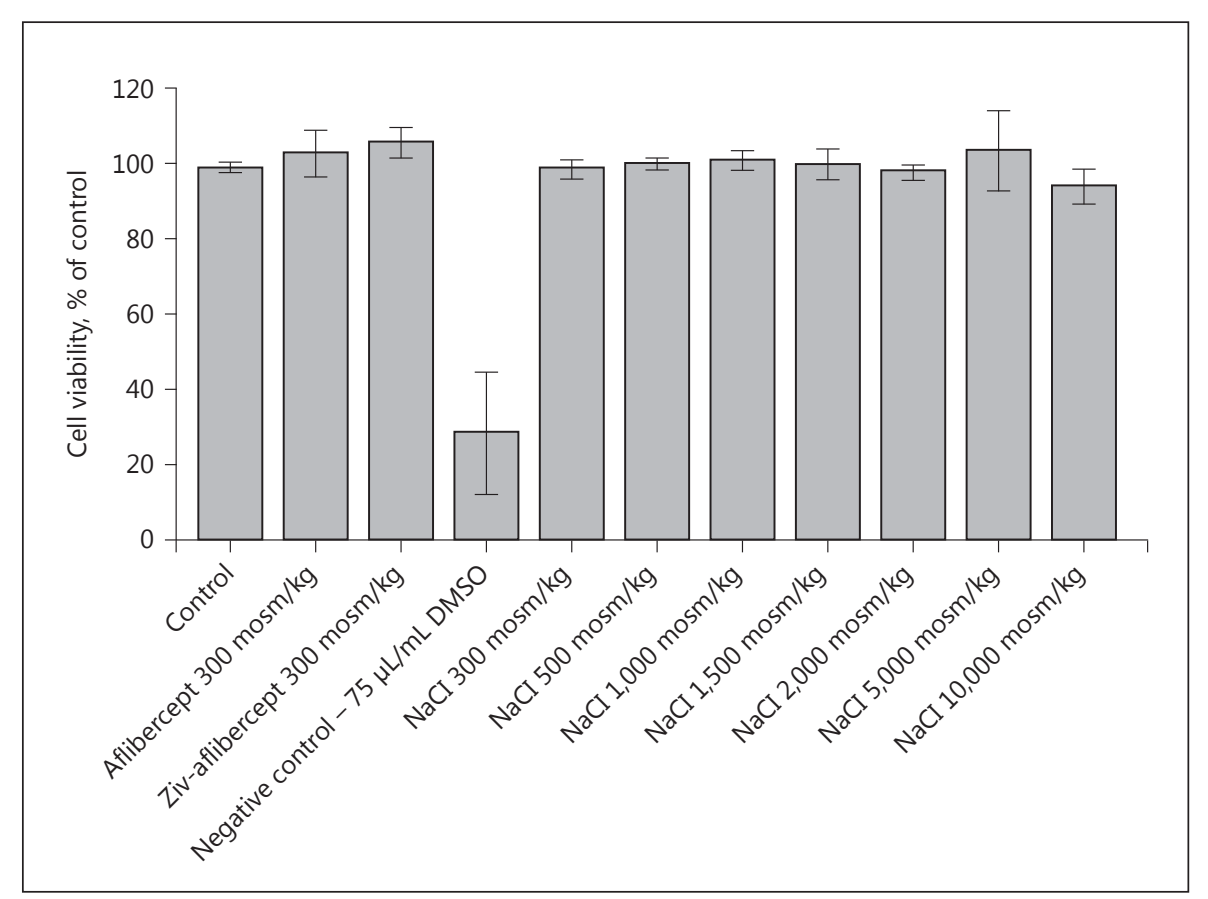

real injection, i.e., 40 and $25 \mathrm{mg} / \mathrm{mL}$, respectively. The volume of the eye was set to be $6 \mathrm{~mL}$. The clinical dose of aflibercept injected into the eye is $2 \mathrm{mg}$. Using this data, it was calculated that $8.33 \mu \mathrm{L}$ of aflibercept and $13.3 \mu \mathrm{L}$ of ziv-aflibercept must be applied to $1 \mathrm{~mL}$ of cell culture medium. Sterile $\mathrm{NaCl}$ (B. Braun, Melsungen, Germany) was brought into solution using distilled water to produce different concentrations of salt solution: 300, 500, 1,000, $1,500,2,000,5,000$, and $10,000 \mathrm{mosm} / \mathrm{kg}$. A dose of $75 \mu \mathrm{L} / \mathrm{mL}$ of dimethyl sulfoxide (DMSO) was used as a negative control.

\section{Cell Culture}

pRPE cells and Mio-M1 cells were used and cultured in uncoated cell culture flasks (NUNC, Langenselbold, Germany) in medium (Dulbecco's Minimum Essential Medium, Biochrom AG, Berlin, Germany) containing 10\% FCS and antibiotics (Biochrom AG, Berlin, Germany) under standard cell culture conditions. For the pRPE cells, only cells from the first three passages were used. Twenty-four hours after subdivision, the serum was removed followed by another $24 \mathrm{~h}$ of incubation with the above described amount of agents under serum-free conditions.

Isolation of Human Primary Retinal Pigment Epithelium Cells Cadaver eyes from two human donors were obtained from the Munich University Hospital Eye Bank and processed within 4 to $16 \mathrm{~h}$ of death. None of the donors had a known history of eye disease. Methods for securing human tissue were humane, included proper consent and approval, complied with the Declaration of Helsinki, and were approved by the local ethics committee. pRPE cells were extracted as described before $[11,12]$.

\section{Cell Viability Assay}

In order to exclude any toxic effects of aflibercept, ziv-aflibercept, or higher osmolalities, it was carefully tested for its biocom- patibility on pRPE and Mio-M1 cells in the XTT assay as described by Scudiero et al. [13] and modified for ocular cell culture biocompatibility testing as described before [12].

\section{Statistical Analysis}

Statistical comparison between different concentrations of Crocin, Resveratrol, and the control was done using the nonparametric Mann-Whitney $U$ Test for comparison of two distinct groups. To prevent multiple testing in more than two subgroups, ANOVA with a Bonferroni post hoc test was used. For all analyses, $p<0.05$ was considered statistically significant with a $95 \%$ confidence interval (CI). All graphs, if not stated otherwise, were plotted in Microsoft Excel showing the standard deviation as error bars. All statistical analysis was performed by SPSS 23.0.

\section{Results}

\section{Cell Viability}

Cell viability was assessed to exclude any toxic effects of both formulations. No statistically significant decrease of cell viability was observed for Eylea or Zaltrap $(p>$ $0.05)$ in all cell lines and in comparison to the control (Fig. 1-3). Furthermore, a change of osmolality in the injection solution up to $10,000 \mathrm{mosm} / \mathrm{kg}$ did not cause any change in cell viability in comparison to the untreated control. The negative control of $75 \mu \mathrm{L} / \mathrm{mL}$ DMSO caused a consistent reduction in cell viability in comparison to all other tested samples (Mio-M1; control - negative con- 
Fig. 3. The change in cell viability in the XTT assay observed for aflibercept or zivaflibercept $(p>0.05)$ in primary human retinal pigment epithelium cells of donor 2 in comparison to the control was not significant. Furthermore, a change in osmolality in the injection solution up to 10,000 $\mathrm{mosm} / \mathrm{kg}$ did not cause any change in cell viability in comparison to the untreated control. A significant decrease was observed in the negative control of $75 \mu \mathrm{L} / \mathrm{mL}$ DMSO.

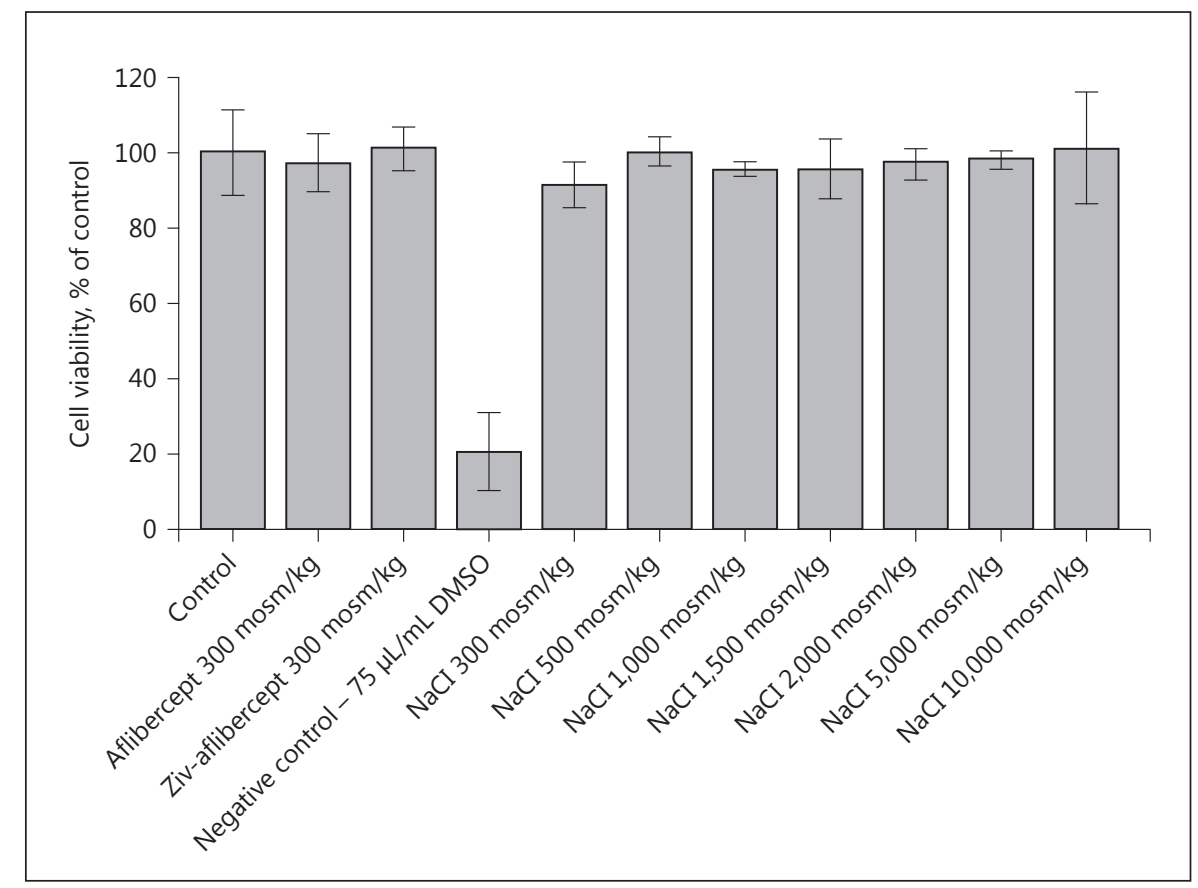

trol; $p<0.001$; mean difference: $79.5 \%$; 95\% CI: 58-100\%) (pRPE 1; control - negative control; $p<0.001$; mean difference: 71.4\%; 95\% CI: 58-85\%) (pRPE 2; control - negative control; $p<0.001$; mean difference: $56.4 \%$; $95 \%$ CI: $38-75 \%)$.

\section{Discussion}

The use of anti-VEGF agents has resulted in a dramatic increase in intravitreal injections in recent years [14]. An analysis of the Medicare claims database revealed fewer than 5,000 intravitreal injections in 2001 and 812,413 in 2007 [14]. Today, intravitreal injection is one of the most commonly performed medical procedures in the United States. More than 2.3 million intravitreal injections were performed in the United States in 2012, and projections call for more than 6 million annually by 2016 [15]. After the introduction of aflibercept, its use has been growing worldwide and besides the great clinical results, the costs regarding this therapy remain an important issue.

Ziv-aflibercept is a similar fusion protein and has shown promising results in the short term $[8,9,11]$. In our previous study of intravitreal ziv-aflibercept for diabetic macular edema, all patients experienced improvement in BCVA and decrease in CRT from baseline till 24 weeks of follow-up [11]. In a prospective noncomparative case series of 6 patients ( 4 with AMD and 2 with refractory diabetic macular edema), intravitreal ziv-aflibercept improved the visual acuity and decreased the central macular thickness. However, the follow-up was only 4 weeks [9].

The study by Malik et al. [7] revealed mild toxicity of bevacizumab and ziv-aflibercept for human retinal pigment epithelium cells (ARPE-19) and may have had a negative impact on the intravitreal use of ziv-aflibercept for macular diseases. In order to access the effect of zivaflibercept in pRPE cells and also in Mio-M1 cells, we decided to compare its effect with aflibercept conventional intravitreal dose and progressive hyperosmolar solutions of $\mathrm{NaCl}$. Many reasons can explain the difference in results from our experiment in relation to Malik's such as: different techniques of obtaining, isolation and culturing RPE cells, cell viability, contamination of the samples, technique, and time of exposure to anti-VEGF.

In summary our study suggests that the exposure of ziv-aflibercept has no different effect on cell viability compared to aflibercept and hyperosmolar $\mathrm{NaCl}$ solutions. Coupled with our recently published report of the lack of in vivo ocular toxicity in rabbits subjected to intravitreal ziv-aflibercept [16], as well as the lack of apparent ocular toxicity seen in human eyes both from the administration of intravitreal ziv-aflibercept in extensive 
off-label use [8--10], all sources of testing suggest that ziv-aflibercept is not associated with significant ocular toxicity. However, formal testing of intravitreal zivaflibercept in the context of randomized clinical trials is warranted before definitive statements regarding its safety and efficacy can be made.

\section{Disclosure Statement}

None of the authors has any financial interest.

\section{References}

1 Rajappa M, Saxena P, Kaur J: Ocular angiogenesis: mechanisms and recent advances in therapy. Adv Clin Chem 2010;50:103-121.

2 Yang R, Thomas GR, Bunting S, Ko A, Ferrara $\mathrm{N}$, Keyt B, et al: Effects of vascular endothelial growth factor on hemodynamics and cardiac performance. J Cardiovasc Pharmacol 1996; $27: 838-844$

3 Stewart MW, Rosenfeld PJ: Predicted biological activity of intravitreal VEGF Trap. Br J Ophthalmol 2008;92:667-668.

4 Yonekawa Y, Andreoli C, Miller JB, et al: Conversion to aflibercept for chronic refractory or recurrent neovascular age-related macular degeneration. Am J Ophthalmol 2013;156: 29-35.

5 Chung C, Pherwani N: Ziv-aflibercept: a novel angiogenesis inhibitor for the treatment of metastatic colorectal cancer. Am J Health Syst Pharm 2013;70:1887-1896.

6 Trichonas G, Kaiser PK: Aflibercept for the treatment of age-related macular degeneration. Ophthalmol Ther 2013;2:89-98.
7 Malik D, Tarek M, Caceres del Carpio J, Ramirez C, Boyer D, Kenney MC, et al: Safety profiles of anti-VEGF drugs: bevacizumab, ranibizumab, aflibercept and ziv-aflibercept on human retinal pigment epithelium cells in culture. Br J Ophthalmol 2014;98(suppl 1): i11-i16.

8 de Oliveira Dias JR, Xavier CO, Maia A, et al: Intravitreal injection of ziv-aflibercept in patient with refractory age-related macular degeneration. Ophthalmic Surg Lasers Imaging Retina 2015;46:91-94.

9 Mansour AM, Al-Ghadban SI, Yunis MH, ElSabban ME: Ziv-aflibercept in macular disease. Br J Ophthalmol 2015;99:1055-1059.

10 de Andrade GC, de Oliveira Dias JR, Maia A, et al: Intravitreal injections of ziv-aflibercept for diabetic macular edema: a pilot study. Retina 2016;36:1640-1645.

11 Eibl KH, Banas B, Schoenfeld CL, et al: Alkylphosphocholines Inhibit Proliferation of Human Retinal Pigment Epithelial Cells. Invest Ophthalmol Vis Sci 2003;44:3556-3561.
12 Wertheimer C, Liegl R, Kernt M, et al: EGF receptor inhibitor erlotinib as a potential pharmacological prophylaxis for posterior capsule opacification. Graefes Arch Clin Exp Ophthalmol 2013;251:1529-1540.

13 Scudiero DA, Shoemaker RH, Paull KD, et al: Evaluation of a soluble tetrazolium/formazan assay for cell growth and drug sensitivity in culture using human and other tumor cell lines. Cancer Res 1988;48:4827-4833.

14 Ramulu PY, Do DV, Corcoran KJ, Corcoran SL, Robin AL: Use of retinal procedures in Medicare beneficiaries from 1997 to 2007. Arch Ophthalmol 2010;128:1335-1340.

15 Williams GA: Intravitreal injections: health policy implications. Rev Ophthalmol 2014;21: 62-64.

16 de Oliveira Dias JR, Badaro E, Novais EA, et al. Preclinical investigations of intravitreal ziv-aflibercept. Ophthalmic Surg Lasers Imaging Retina 2014;45:577-584. 